Trabajos y Comunicaciones, 2da. Época, № 47, e052, enero-junio 2018. ISSN 2346-8971

Universidad Nacional de La Plata.

Facultad de Humanidades y Ciencias de la Educación.

Departamento de Historia

\title{
Constelaciones conflictivas en la industria pesquera bonaerense. Análisis comparativo entre Mar del Plata y Necochea, Argentina (1997-2012)
}

\section{Conflicting constellations in the bonaerense fishery industry. Comparative analysis between Mar del Plata and Necochea, Argentina (1997-2012)}

\author{
María Luciana Nogueira * \\ * CONICET-Grupo de Estudios Sociales Marítimos \\ Universidad Nacional de Mar del Plata, Argentina | nogueiramluciana@gmail.com
}

PALABRAS CLAVE

Conflictividad sociolaboral

Industria pesquera Bonaerense

Reestructuración capitalista

\section{RESUMEN}

Este trabajo consiste en una descripción analítico-interpretativa desde una perspectiva comparada de las constelaciones de la conflictividad sociolaboral en dos ciudades portuarias argentinas. Las categorías de análisis utilizadas fueron: las modalidades de acción, los sujetos que las llevaron a cabo, los objetivos perseguidos y las alianzas con otros actores sociales. Las fuentes provinieron de las prensas gráficas, entrevistas y bibliografía académica. A partir del análisis de los datos se detectaron tres campos de disputa intrincados, cruciales para la comprensión de los avatares de la industria pesquera luego de la reestructuración capitalista neoliberal.
KEYWORDS

Socioloboral Conflict

Buenos Aires Fishing Industry

Capitalist Restructuring

\section{ABSTRACT}

This work consists of an analytic-interpretative description from a comparative perspective the constellations of the socio-labor conflict in twoargentinians port cities. The analytical categories used were the modalities of action, the subjects that carry them out, the objectives they pursue and the alliances with other social actors. The sources were the local graphic presses, interviews and previous studies. From the analysis of the information, three intricate fields of dispute were detected, crucial for the understanding of the avatars of the fishing industry after neoliberal capitalist restructuring. 


\section{Introducción}

El objetivo de este trabajo consiste en abordar, desde una perspectiva comparada, las constelaciones de la conflictividad sociolaboral ligadas a la industria pesquera argentina en dos ciudades portuarias de la provincia de Buenos Aires, correspondientes a los puertos de Mar del Plata y Quequén-Necochea entre los años 1997 y 2012. El mismo, forma parte de los avances de investigación en el marco de mi proyecto de Tesis Doctoral en curso. ${ }^{1} \mathrm{La}$ investigación guarda un carácter sociohistórico, dado que conjuga el impacto específico en la actividad pesquera comercial marítima nacional de la reestructuración capitalista que inició en los '70 -y se profundizó en los '90con las crisis propias del sector. Al mismo tiempo, se le otorga especial importancia a las subjetividades obreras que atraviesan los procesos en cuestión. Desde este encuadre se focaliza el análisis tanto en las acciones obreras como en su impacto subjetivo en quienes las protagonizaron. En el período abordado se destacan como características predominantes la sobreexplotación del recurso pesquero, las renovaciones tecnológicas, la creciente monopolización y los concomitantes cierres por absorción y quiebra de pequeñas y medianas empresas, que implicaron el desguace del sector en determinadas localidades bonaerenses. Estas características, a su vez, se vinculan con otras de las décadas anteriores, propias de la instauración de la reestructuración capitalista (Grigera, 2012) a nivel mundial en los '70 y sus impactos sobre las economías nacionales y regionales de América Latina.

Para analizar la conflictividad sociolaboral en la historia reciente de la industria pesquera bonaerense, aquí presentamos como hipótesis que las consecuencias de la reestructuración capitalista fueron la desocupación y el aumento de la precarización laboral, tanto en términos de las condiciones de producción como de contratación. Esto habilitó diversas acciones de rebelión obrera ante las duras condiciones impuestas por el capital, así como también disputas entre la propia burguesía y en torno a la organización sindical. En su conjunto, los campos de disputa intrincados se vinculan en forma dialéctica unos con otros (Marx, 1873; Mandel, 1977), en una recíproca influencia y mutua co-construcción. Por ello, los casos de Mar del Plata y Necochea son ilustrativos de diferentes desenlaces de la reestructuración capitalista en el sector industrial pesquero y de las resistencias frente a ella, en el marco de una conflictividad sociolaboral concebida como parte del movimiento mismo de la sociedad, esto es, en la lucha de clases y la conflictiva intra-clase.

El Puerto de Mar del Plata fue concebido y concretado como el complejo pesquero argentino por excelencia desde los inicios de la actividad pesquera comercial marítima nacional (Mateo, 2011). En este puerto se concentró la primera gran comunidad de pescadores y las más grandes plantas procesadoras de pescado, las cuales se consolidaron primero en la década del ' 30 y luego durante la segunda guerra mundial. Desde la década del ' 70 , la relocalización de parte del sector extractivo e industrial en los puertos patagónicos -impulsada por el estado y las grandes empresas, en alianza con el capital trasnacional- restó preminencia al puerto marplatense, que igualmente continuó destacándose en el sector de procesamiento fresquero y la pesca de altura; mientras que la Patagonia se dedicó mayormente a la pesca con buques factoría y con congelado a bordo. Esta relocalización y concentración de la operatoria pesquera se conjugó con los acuerdos marco con terceros países realizados por los gobiernos de Alfonsín y Menem, y con el otorgamiento de permisos de pesca a flotas extranjeras.

Estos cambios, sumados a las características mencionadas del período 1997-2012,permitieron una ofensiva patronal contra las condiciones de trabajo y contratación, fomentando la proliferación de cooperativas fraudulentas en la industria pesquera marplatense. Esta maniobra de fraude empresarial, en connivencia con el estado y los gobiernos, permitió engrosar las filas de trabajadores no registrados, así como las de los desocupados en la rama. Los trabajadores de la pesca marplatense presentaron combate ante esta coyuntura adversa, tanto en forma orgánica como por fuera de la organización sindical y contra ella.

En contrapartida, el sector pesquero en la ciudad de Necochea se desarrolló inicialmente como correlato del gran crecimiento marplatense, actuando de forma apendicular al igual que otras ciudades portuarias de la provincia de Buenos Aires (tales como Claromecó, San Bernardo, entre otras), más pequeñas con relación a Mar del Plata. Pero aquí el camino fue diferente al de la gran ciudad, mientras que la tendencia hasta los ' 70 fue la de un gran ciclo expansivo en cuanto a cantidad de plantas y fuerza de trabajo empleada, posteriormente la relocalización portuaria en la Patagonia y la concentración de las firmas y los mercados generó la desaparición progresiva de este enclave 
industrial de menor envergadura (Nogueira, 2017). Esta desaparición progresiva del sector también generó una resistencia obrera organizada sobre el final del ciclo, cuando dos colectivos obreros decidieron ocupar sus lugares de trabajo en vistas a preservar las fuentes laborales.

\section{Aclaraciones metodológicas}

La crisis y reconfiguración propia de la actividad pesquera argentina se enmarca en el proceso global de reestructuración capitalista a nivel mundial, que a partir de los '70 instauró un nuevo patrón de acumulación basado en un modelo neoliberal. El aumento de la desocupación, el trabajo en negro y en ramas ilegales, la flexibilización y la tercerización fueron los resultados de estas políticas neoliberales aplicadas al mercado laboral, que se profundizaron en la década del 90 cuando los Estados adoptaron los requerimientos del Consenso de Washington. La cooperativización y el cuentapropismo o "autoempleo" (Rebón, 2004) comenzó a crecer junto con la desocupación y el trabajo no registrado, mientras que la precarización se constituyó como una característica transversal del trabajo asalariado en términos de empeoramiento de condiciones de producción y contratación, con una mayor explotación y opresión. Estos cambios en las esferas económica, política, social, cultural y laboral impactaron en las subjetividades obreras, que transformaron sus representaciones, vivencias, concepciones y emociones con respecto al trabajo y su posición de trabajadores (Antunes, 2007; Dejours, 2013), cambios que se tradujeron en diversas acciones de organización y combate.

En este sentido, cabe mencionar una revitalización de la lucha organizada del movimiento obrero argentino en las últimas décadas (Nieto, 2010) que -sin desconocer la persistencia de la lucha y resistencia en la totalidad del período neoliberal-, marca un nuevo pulso en la protesta social desde fines de los ' 90 , cuando luego de un período en donde predominaba el consenso, la fragmentación y el individualismo (Izaguirre, 1994) comenzó a ampliar su notoriedad la protesta callejera ante el empeoramiento en las condiciones de vida y trabajo de la clase obrera. Particularmente, dentro de la rama a nivel nacional ${ }^{2}$ la conflictividad creciente se expresó en el marco de la crisis de un sistema productivo ligado fuertemente a la convertibilidad y atado a la sobreextracción de la merluza (Nieto, 2010; Colombo, 2008). Posteriormente, el contexto de la posconvertibilidad posibilitó una recuperación y crecimiento económico empresarial y a la vez generó transformaciones en las luchas obreras, cambios que se conjugaron con la continuidad de ciertas demandas y formas de lucha precedentes.

En el eje de las continuidades que atraviesan todo el período estudiado podemos ubicar al gran incremento de la cooperativización en la industria pesquera argentina. La precarización y la expulsión de mano de obra asalariada fueron la contracara del cierre por absorción y/o quiebra de numerosos establecimientos fabriles y la conformación de grandes grupos económicos de la pesca. Estos últimos, productos de la creciente concentración capitalista y de la asociación de capitales nacionales y extranjeros, empezaron a abarcar la totalidad del circuito productivo desde la extracción hasta la comercialización, con ventas orientadas fundamentalmente hacia la exportación. A fin de aumentar su margen de ganancia despidieron gran parte de la fuerza de trabajo asalariada para luego recontratar a muchos de esos trabajadores como socios de cooperativas, formato laboral que "enmarca una aparente legalidad, disfraza al trabajador de asociado y al testaferro del empresario en presidente de la cooperativa" (Mateo, Nieto \& Colombo, 2010: 234). Esta forma de trabajo precarizado/tercerizado es adoptada por los grandes grupos económicos pesqueros como estrategia de obtención de beneficios lucrativos a costa de una superexplotación obrera por la cual el trabajador aporta la fuerza de trabajo, pero tanto la materia prima como la posterior comercialización del producto y su ganancia están a cargo del propietario de la empresa. La intensificación de la explotación obrera opera desde múltiples aristas en un espectro que abarca desde la carencia de regulación propia del convenio colectivo de trabajo para su sector (lo que implica la pérdida de garantías horarias, salariales, antigüedad, salario familiar, vacaciones, aguinaldo, entre las más destacadas) hasta el empeoramiento de las condiciones de trabajo con un mayor grado de inestabilidad, incertidumbre y riesgo laboral (Cutuli, 2009). A su vez, contribuye a la división de los trabajadores en cuanto a métodos, objetivos y posibilidades de lucha contra la explotación y la opresión capitalista en sus múltiples formas. 
Esta división al interior de la fuerza de trabajo fomentada por los empresarios mediante diferentes modalidades de contratación y superexplotación es denominada por algunos autores como dualización o segmentación de la fuerza de trabajo (Monereo Pérez,2000 y Antunes, 2007). Este es uno de los mecanismos utilizado por la clase dominante para dividir y debilitar la lucha de la clase obrera contra el capital en el marco de la reestructuración capitalista, el cual opera en la globalidad de los ámbitos de trabajo y sectores productivos. En el sector pesquero, en Argentina, este mecanismo logró instalarse -a nuestro parecer- fundamentalmente por dos razones: por un lado, el proceso productivo presenta una fuerte dependencia a las posibilidades extractivas, las cuales son extremadamente variables ya que se encuentran sujetas a diversos factores, algunos de ellos imposibles de prever y controlar por el capital (tales como condiciones climáticas y desarrollo de la biomasa pesquera); esto provocó que incluso la lucha por el convenio más avanzado en cuanto a derechos laborales del sector pesquero nacional -el Convenio 161/75no consiguiera eliminar el trabajo a destajo en la rama fresquera, subrama en la que se crearon la mayoría de las cooperativas fraudulentas. Al estar la producción tan afectada por la materia prima disponible, las condiciones de producción no logran ser regulares ni previsibles, por lo que los empresarios se niegan a otorgar ciertas garantías a los trabajadores. La cooperativización fraudulenta puede definirse como una masificación del trabajo a destajo sin ningún tipo de garantías incluidas en el convenio colectivo del sector, a la vez que elimina aportes patronales y otras cargas sociales a cargo del empleador, como una forma de transferir al trabajador los riesgos propios de la producción y comercialización en el sector pesquero. El otro motivo es el amparo legal con que los empresarios pesqueros cuentan para utilizar fuerza de trabajo no registrada sin ningún tipo de obstáculo jurídico, incluso mediante las facilidades que la Ley de Cooperativas 20.337 les otorga, sumado a la complicidad de los organismos del poder judicial y del Ministerio de trabajo que desconocen la denuncias obreras y sindicales sobre el trabajo no registrado enmascarado bajo la forma de las cooperativas.

En un sentido similar, bajo el paradigma de la "Economía Social" (Zamagni, 2000; Singer, 2002; Coraggio, 1991; Laville, 2002; Gandulfo, 2014) distintos estados latinoamericanos han promovido la cooperativización de la fuerza de trabajo como una medida correlativa al desempleo estructural de las últimas décadas, transfiriendo a la clase obrera la responsabilidad de autoemplearse. En este marco, en Argentina comenzaron a implementarse políticas públicas en vías de permitir e incentivar la creación de cooperativas (Nogueira, 2017), tanto en casos de desocupación como en el marco de procesos de cierre empresarial por quiebra o fuga de capitales. Debido a ello, lograron sobrevivir experiencias de autogestión obrera mediante la reactivación de empresas abandonadas por la patronal, como estrategia laboral obrera para evitar la desocupación. En este marco se incluyen dos empresas pesqueras recuperadas en la ciudad de Necochea, primeros casos en el rubro a nivel nacional. A diferencia del cuadro marplatense, aquí la iniciativa de cooperativización provino de los trabajadores -en muchos casos, motivados por el estado u otras organizaciones sindicales, políticas, y sociales-, con mayor o menor oposición de la patronal y en el marco de acciones conflictivas. Sin embargo, una vez lograda la posibilidad de seguir produciendo y comercializando bajo su propia gestión, cabe preguntarse por las similitudes y diferencias con las condiciones precarias de trabajo de los obreros que integran las cooperativas fraudulentas en la industria pesquera marplatense.

Para abordar el objeto en cuestión en este trabajo, utilizaremos el término constelación $\underline{\underline{3}}$ para metaforizar la diversidad de acciones sociolaborales conflictivas, dado que las mismas pueden subagruparse en campos de disputa marcados por distintas variables que plasman "figuras" específicas, en una mutua correlación permanente. A fin de detectar y precisar los rasgos constitutivos de estas constelaciones en el universo de la conflictividad de la industria pesquera bonaerense, se utilizaron categorías analíticas propias de la Base de datos del Seminario de Investigación sobre el Movimiento de la Sociedad(SISMOS), $\underset{4}{4}$ tales como las modalidades de acción, los sujetos que las llevan a cabo, los objetivos que persiguen, las alianzas con otros actores sociales -incluyendo a la organización sindical-y las demandas hacia el Estado.

Para la obtención de la información se apeló a una diversidad de fuentes, a fin de contrastar los datos obtenidos de cada uno de ellas mediante un análisis crítico multicausal. Por un lado, se realizó un minucioso análisis de las prensas graficas locales de ambas ciudades abordadas. Para el caso de Mar del Plata, el periódico elegido fue el 
Diario "La Capital”, mientras que en Necochea solo existe un único medio impreso en forma diaria, llamado “Ecos Diarios”. En esta última localidad, la muestra recopilada corresponde al período 2010-2013, lapso en el cual acontecieron los cierres de las últimas plantas procesadoras de pescado que quedaban funcionando en la ciudad. En dos de ellas, se llevaron a cabo las recuperaciones de empresas por parte de los trabajadores, procesos que referimos anteriormente. Para el caso marplatense se utilizaron ejemplares correspondientes a determinadas acciones conflictivas emprendidas por los diversos sujetos en lucha. Asimismo, fueron consultados otros diarios digitales marplatenses a fin de rescatar otros datos no incluidos en la prensa gráfica, así como algunos ejemplares de la Revista Puerto. Considerada en su conjunto, la información extraída de las notas de prensa seleccionadas proporcionó datos acerca de las acciones conflictivas realizadas, su formato específico, día y lugar de realización, organizaciones intervinientes, objetivos y resultados de la acción, y asimismo fue posible localizar citas de declaraciones que contenían valoraciones de los propios actores involucrados: trabajadores, dirigentes gremiales, empresarios, funcionarios gubernamentales.

Por otra parte, otras fuentes de información fueron entrevistas a los actores, principalmente trabajadores, pero también algunos representantes sindicales. Para el caso de Necochea se realizó un total de 12 entrevistas. En el caso de la Recuperada tres de ellas fueron grupales, a las que se sumaron cinco individuales; las primeras se efectuaron en octubre del 2011, una se realizó en octubre de 2013 y las últimas entre febrero y abril de 2014. Luego, se llevaron a cabo dos entrevistas grupales en la empresa autogestionada Engraucoop, la primera en octubre de 2012 y la segunda en octubre de 2013. Por último, un entrevistado es pescadero local, propietario de embarcaciones, nieto de uno de los primeros pescadores de la ciudad radicado en la década del '40, y otro es abogado del Sindicato de la Alimentación, sede Necochea. En cuanto a la ciudad de Mar del Plata, hasta el momento se hizo uso de una decena de entrevistas transcriptas realizadas en el marco de la materia "Metodología cualitativa" correspondiente a la carrera de Sociología de la UNMdP. Ellas son el resultado de un trabajo práctico aplicado de Investigación cualitativa dirigido por la docente Alejandra Navarro durante el año 2009.

Para recolectar información sobre el proceso necochense, también se implementó la técnica de la observación participante en acciones emprendidas por los colectivos obreros de la Recuperada y Engraucoop, la cual se implementó en dos festivales realizados en cada una de las plantas procesadoras -uno en 2011 y otro en 2012 - y en cuatro Fiestas recuperadas de los pescadores entre los años 2012 y 2015.

A su vez, como fuentes secundarias se utilizaron trabajos previos de otros investigadores dedicados principalmente a los obreros pesqueros marplatenses, las cuales aportaron un gran caudal de variada información al respecto que se encuentra debidamente citada en los desarrollos que prosiguen.

Luego de interpretar la información obtenida, se detectaron tres campos de disputa intrincados: interburgués, sindical y capital/trabajo, de aquí que el aporte específico de este trabajo reside en la correlación entre estos campos de disputa desde una perspectiva comparada entre ambas localizaciones portuarias bonaerenses.

\section{Discusión}

La reestructuración capitalista se conjugó con la reconfiguración propia de la actividad pesquera, que tuvo su momento crítico en el año 1997 con la crisis por sobrepesca de la merluza, recurso pesquero por excelencia. Por ello, el período entre los años 1990 y 2012 se caracterizó por una expansión y crisis de la industria merlucera, asociada a la proliferación de las grandes embarcaciones con congelado y/o procesado a bordo, la extranjerización de la flota, la superexplotación del recurso y la ya mencionada división del sector entre los puertos de Mar del Plata y la Patagonia. La apertura externa implicó una mayor competencia y sobrecapitalización, la cual asociada a la sobreexplotación de la merluza condujo a parte del empresariado a la quiebra, con la concomitante concentración y aumento de la monopolización de la actividad en manos de un puñado de grandes empresas de asociación de capitales nacionales y extranjeros (Joints Ventures). Las mismas aprovecharon este contexto para adoptar medidas de superexplotación laboral a fin de intensificar su tasa de ganancia; entre esas medidas se destaca la conformación de cooperativas fraudulentas, que para el año 1996 alcanzaban al 42\% del total de 
obreros de la industria pesquera..

Esta forma de precarización laboral no es privativa del sector pesquero ni de Argentina, aunque en la rama estudiada se manifieste notoriamente a lo largo de los últimos 25 años (Mateo, Nieto y Colombo, 2010: 37-38). La cooperativización fraudulenta se reproduce a escala mundial, como lo expresan las pesquisas de Ramirez Rojas y Guevara Fletcher (2006), Ermida, Uriarte y Colotuzzo (2009) y Alvarez (2007). En Argentina, diversos estudios muestran que los trabajadores más afectados por este formado de empleo no registrado se desempeñan en ramas industriales con alta estacionalidad laboral, destacándose las ramas agroindustriales (Mateo, Nieto y Colombo, 2010; Bendini y Gallegos, 2002; Alfaro, 2003; Worcel, 2006).Por otra parte, la quiebra de numerosas empresas no solo produjo despidos y precarización laboral, sino que para el caso necochense significó el desguace de la mayor parte del sector industrial perteneciente a la rama, desmantelamiento progresivo que inició en la década del ' 80 y culminó en el año 2012, cuyos sobrevivientes fueron un puñado de obreros de la pesca que recuperaron dos plantas procesadoras bajo gestión obrera.

Estas transformaciones provocaron un reordenamiento de las relaciones productivas, a la vez que una redefinición y reacomodo delos agentes que los protagonizaron, sujetos que hasta ese momento eran trabajadores formales dependientes dentro de una estructura vertical de empleo registrado. De acuerdo a la información recolectada, a grandes rasgos podemos distinguir que las consecuencias de estos procesos en el plano de las subjetividades obreras tendieron a ordenarse en dos polos: por un lado el segmento de trabajadores de las cooperativas fraudulentas de fileteado de Mar del Plata, que dio origen a una organización obrera contenciosa y rebelde a las nuevas condiciones impuestas por la hegemonía neoliberal; y por otra parte, el segmento de trabajadores autogestionarios de Necochea que se enfrentaron en el terreno de la producción con el sistema de pensamiento hegemónico presente en la sociedad en su conjunto. Esto último hace referencia a que en la mayoría de los casos de cierre empresarial por quiebra, el camino previsto por el empresariado y el Estado es el retiro pacífico de los trabajadores una vez despedidos, en el marco de la resolución individual de su destino de desocupación y falta de ingresos a través de la búsqueda de un nuevo empleo, realización de changas y una prolongada disputa particular en el ámbito judicial en vistas de obtener el pago de las indemnizaciones. Entonces, en la mayoría de los casos, los trabajadores no recuperan las empresas fallidas; por el contrario, de los miles de empresas que cierran por procesos de quiebra, solo un puñado de cientos fueron luego recuperadas (Brunet y Pizzi, 2011). En estos casos, el colectivo obrero logra romper con la lógica individualista dominante y, junto con otras organizaciones y personificaciones sociales que brindan apoyo y recursos -políticos, organizativos y subjetivos-, emprende una lucha por conservar sus puestos de trabajo en la empresa fallida mediante la autogestión obrera. Más allá de los posteriores desenlaces de cada caso, el camino autogestivo aparece como una salida obrera y contra hegemónica al destino de pobreza y desempleo promovido por el empresariado.

Tomados en su conjunto, los trabajadores cooperativizados de ambas ciudades portuarias emprendieron un variado repertorio de acciones de rebelión a fin de resistir a la precarización laboral y los despidos. Por su parte, el sector asalariado registrado también llevó a cabo gran cantidad de hecho de rebelión en el contexto de crisis, precariedad laboral y escasez del recurso. Sin embargo, los obreros no fueron los únicos protagonistas de este universo conflictivo, que también registró acciones llevadas a cabo por empresarios, funcionarios del gobierno y gremialistas. Comenzaremos puntualizando el campo de disputa interburgués.

\section{La disputa interburguesa: la multisectorial marplatense vs. los pulpos pesqueros}

Antes de comenzar a explayarnos al respecto, cabe aclarar que en este apartado nos abocaremos casi por entero al caso marplatense, ya que para el caso de Necochea hasta el momento no hay registros de grandes confrontaciones entre empresarios, y por ello el conflicto aquí puede resumirse en el cierre progresivo de las plantas procesadoras de pescado, proceso que culmina en febrero de 2012 con la quiebra de la última planta que se encontraba funcionando en la ciudad. Aquí el conflicto interburgués puede resumirse en la derrota del empresariado pesquero local por absorción o asfixia del gran capital concentrado en Mar del Plata y la Patagonia. 
En la localización marplatense, la crisis originada por la sobrepesca de merluza en 1997 fue el punto de inflexión para la disputa entre dos sectores empresariales diferenciados. Esta crisis significaba para la burguesía la contracción de posibilidades de extracción, no solo por las vedas y cupos de pesca impuestos por el Estado sino también por la escasez real del recurso producto de la excesiva depredación previa. Las capturas debían reducirse inevitablemente, lo que generó una disputa por dirimir quién restringiría menos su tasa de ganancia a causa de la escasez de materia prima, o, dicho de otra manera, quién pagaría el costo de la sobrepesca y sobrecapitalización de la industria. La división y pugna entre un empresariado pesquero dedicado exclusivamente a la producción fresquera, por un lado, y los grandes grupos económicos de la pesca que habían acrecentado su monopolización enormemente en las últimas décadas, por el otro, se acentuó y consolidó como una pulseada ante la crisis del recurso. Al respecto, de acuerdo a Colombo (2014) si bien las disidencias entre ambos grupos del empresariado pesquero marplatense existían previamente, hasta ese momento había primado la ausencia de conflicto entre ambos. Este consenso parcial se rompe al final de la década del '90, cuando cada sector buscó que la crisis recaiga sobre el otro. La obtención de cuotas de captura disponibles y luego la orientación de una nueva Ley de Pesca que incluía determinadas restricciones y medidas proteccionistas- fueron los objetivos de ambos bandos empresariales.

Esta disputa implicó agrupamientos y alianzas, conformándose por un lado la Multisectorial pesquera como organización que nucleaba a los empresarios fresqueros y por otra parte el Consejo de Empresas Pesqueros de Argentina (CEPA) como institución propia de las grandes corporaciones.

La Multisectorial pesquera marplatense estuvo integrada por empresas dedicadas a la industrialización de pescado fresco incluidas en la Cámara Argentina de Armadores de Buques Pesqueros (CAABP) y la Cámara de Procesadores, sumándose funcionarios gubernamentales entre los que se encontraba el intendente marplatense Aprile y también gremios pesqueros entre los que se destacan el SOIP (Sindicato obrero de la industria del pescado), el SOMU (Sindicato de obreros marítimos unidos) y el SUPA (Sindicato Unidos portuarios argentinos). Asimismo, una amplia base de trabajadores de la pesca (marineros, estibadores y de la industria) apoyó esta alianza y participó de las acciones masivas que impulsaba.

La Multisectorial se enfrentaba a los llamados "Pulpos pesqueros", empresarios de origen marplatense pero que, a raíz de la reestructuración capitalista y su asociación con capitales extranjeros, se convirtieron en empresas integradas incluyendo todo el circuito pesquero desde la extracción hasta la comercialización, con su propia flota de altura y de factoría, con producción de pescado fresco y congelado, y localización tanto en Mar del Plata como en ciudades portuarias de la Patagonia. Las firmas integrantes son: Moscuzzae Hijos S.A., Giorno S.A. (Valastro), Luis Solimeno e Hijos S.A. y Santa Elena S.A.

Identificamos entonces a los actores de esta disputa interburguesa: la confrontación se produce entre una "burguesía fresquera" vs. los "grandes grupos económicos de la pesca".

Las precursoras de la Multisectorial son reuniones entre empresarios fresqueros, gremios e intendente, que impusieron como enemigo común a las grandes empresas y a los buques congeladores de la Patagonia. En su discurso predominaba como relato el proyecto local marplatense para la provincia de Buenos Aires, fundamentado en el valor de la "tradición" y la generación de empleo con tintes localistas y nacionalistas. (Colombo, 2014) La designación de Héctor Auguste como Subsecretario de Pesca desencadenó la unión policlasista, ya que Auguste hasta entonces había sido presidente de la CAPECA, nucleamiento comandado por empresarios de la CEPA. Por lo tanto, era fácil prever a qué intereses burgueses favorecería. El proyecto de la Multisectorial apuntaba a obtener para el empresariado marplatense los mismos beneficios que gozaban los puertos del Sur -es decir, los buques con procesado a bordo- en términos de subsidios y reducciones impositivas, así como también lograr la expulsión bajo el paralelo $48^{\circ}$ de los buques factoría y disponer de la prioridad en las capturas permitidas. Para garantizar la posibilidad de plantear este proyecto contra los grandes grupos económicos, la burguesía fresquera confluyó en una alianza de clases con una fracción de los trabajadores y los sindicatos (Colombo y Nieto 2006). 
Por su parte, los grandes empresarios nucleados en la CEPA proyectaban un "plan de promoción a la producción y a las exportaciones pesqueras" (Colombo, 2014), el cual incluía un reintegro por las exportaciones, reducciones impositivas, rebaja de aranceles para la importación de maquinarias y equipos y tasas preferenciales de créditos, cuyo fundamento residía en la mayor eficiencia, tecnificación y modernización.

Las modalidades de acción de ambos bandos empresariales fueron diversas, abarcando un espectro que va desde reuniones entre partes con distintos funcionarios gubernamentales a nivel provincial y nacional hasta masivas movilizaciones a Buenos Aires, como medio de presión al gobierno nacional para la promulgación de leyes, decretos y disposiciones a su favor. Entre las conquistas legales, su mayor exponente fue la Ley de Emergencia Pesquera 25.109, sancionada el 23 de junio de 1999. Al respecto de esta ley, si bien fue el objetivo primordial del agrupamiento multisectorial, su conquista no implicó mayores pérdidas para los grandes grupos económicos. Esto se debe a que su sanción fue precedida por un decreto presidencial que levantaba una veda, cuyo texto permitía que los grupos empresarios que contaban con buques congeladores puedan seguir pescando si acreditaban la posesión de plantas en tierra -situación que es generalidad en las empresas nucleadas en la CEPA- (Colombo, 2014).

La primera marcha a Buenos Aires con bloqueo del puerto fue realizada por la multisectorial a raíz de la amenaza del cierre del caladero de Mar del Plata, motivada por esa estricta veda impuesta desde el Consejo Federal Pesquero en mayo de 1999. La movilización se realizó el 2 de junio y participaron más de 90 barcos y 4.000 manifestantes, contando con el apoyo de más de 80.000 personas que fueron al puerto a despedir a los barcos que partían hacia la Casa Rosada. Como resultado de esta movilización se logró la aprobación de la Ley de Emergencia pesquera, que contenía la mayoría de las demandas del empresariado fresquero y fortaleció así la alianza policlasista. Posteriormente, la invariabilidad de la situación precaria de los trabajadores produjo un momentáneo quiebre de la multisectorial, con el retiro del SOMU y el SOIP a causa de la desatención de los propios reclamos. Sin embargo, a pesar de la sanción de dicha ley el problema de la escasez del recurso persistió, por lo que fue necesario fijar nuevas cuotas de captura máxima permisible y nuevas vedas que provocaron un recrudecimiento del conflicto interburgués y, por ende, la reinstalación de la alianza multisectorial basada en la hipótesis del enemigo en común.

En el año 2000, luego de meses de numerosos conflictos locales, el 10 de mayo se produce una nueva manifestación masiva en la ciudad de Buenos Aires organizada por la Multisectorial. Más de 6 mil personas vinculadas a la pesca se movilizaron a Plaza de Mayo, obteniendo un nuevo compromiso del gobierno nacional para declarar la emergencia pesquera. ${ }^{6}$ No obstante, al día siguiente moviliza la CEPA y también obtiene un compromiso a su favor (Colombo, 2014: 392). De esta forma observamos la oscilación de los gobiernos de turno y de los funcionarios intervinientes en su apoyo o perjuicio a uno u otro sector, predominando los acuerdos parciales y transitorios basados en necesidades económicas y comerciales, desestimando como factor de preponderancia la real disponibilidad sustentable del recurso merlucero.

Pero el agotamiento del recurso era real, tal como lo demostrara el INIDEP en numerosos estudios sucesivos, y los gobiernos solo aplicaron medidas breves y parciales, dado que no tenían intención de modificar la política económica de fondo, que a nuestra interpretación no fue más que dejar a disposición de todos los empresarios (grandes y pequeños, nacionales, extranjeros y mixtos) el recurso pesquero. No sorprende entonces que la resolución de este conflicto se vincule con la necesidad del ajuste fiscal impositivo impuesto por la crisis de la convertibilidad en Argentina -con la concomitante crisis de deuda y de reservas, entre otros aspectos-, ante el anuncio del cobro de una tasa por parte del estado, aplicable a las empresas que realicen extracción ictícola en aguas nacionales. En consecuencia, ambos bandos empresariales se unieron para repudiar la medida tomada por Ernesto Godelman, funcionario de la Dirección de Pesca durante el gobierno de De la Rúa, que versaba sobre la reducción general de los cupos de pesca de merluza y el cobro de aranceles en calidad de derechos de extracción destinados a un fondo nacional pesquero. Ante ello, iniciado el 2001 la Cámara de Procesadores, la CAABPA, UDIPA y el CEPA -es decir, el conjunto del empresariado- entregaron al intendente marplatense un documento en el que proponían medidas generales para la continuidad de la actividad pesquera nacional(Colombo, 2014). Luego 
de salir victoriosos en la pulseada conjunta contra esta medida gubernamental, la burguesía pesquera selló un acuerdo tácito de tregua que predomina hasta hoy, aunque no sin fricciones momentáneas. La posterior virtual recuperación del recurso pesquero fue otro de los sustentos materiales para la unificación del empresariado, quien retomó su convivencia pacífica en el marco de la competitividad mercantil.

Los trabajadores que fueron tras las demandas del empresariado fresquero en el camino se encontraron con otras disputas tanto con el capital como con sus gremios representantes.

\title{
La disputa sindical: entre la tregua y la combatividad
}

En este campo de disputa nos centraremos en las acciones del SOIP en Mar del Plata y del Sindicato de la Alimentación en Necochea, y para el caso marplatense mencionaremos algunos conflictos en los que se involucró el SOMU, que si bien representa a los trabajadores embarcados en muchas ocasiones actuó traccionando y cuestionando el accionar del SOIP en el período abordado, y por ello resulta relevante y pertinente su inclusión en el análisis.

Dentro del conflicto iniciado en 1997, si bien tanto el SOIP como el SOMU apoyaron al empresariado fresquero aliado con el gobierno local, la conducción del SOMU impulsó al mismo tiempo medidas de protesta propias por reivindicaciones laborales y salariales. Estos reclamos obtuvieron respuesta positiva por parte del empresariado, pero en todas las ocasiones con mediación de huelgas (Colombo y Nieto, 2008). La dirigencia del SOIP, en cambio, mantuvo una posición de tregua con respecto a las demandas obreras, argumentando las más de las veces que la metodología del paro beneficiaba a los grandes grupos económicos de la pesca y por ello no había que utilizarla hasta tanto se dirimiera el conflicto interburgués (Nieto, 2010: 12). De esta forma relegaba las demandas propias de los trabajadores por las demandas empresariales, definición que con el tiempo comenzó a ser cuestionada por las bases, sobre todo luego de la gran proliferación de cooperativas fraudulentas posterior a 1997. Si bien el SOIP venía denunciando en los canales institucionales a las cooperativas fraudulentas, mantuvo sus reclamos dentro de las vías formales (tales como presentación de cartas a distintos organismos del estado) sin realizar otras acciones combativas al respecto, y quedando las mismas sin efecto (Colombo, 2014:393). Incluso algunos trabajadores señalan que el SOIP actuó incitando el pasaje pacífico de los trabajadores despedidos hacia las cooperativas fraudulentas. Así lo relata una trabajadora:

\begin{abstract}
"Nuestros dirigentes iban a las fábricas y nos decían 'porque estar en las cooperativas no es malo, es bueno, van a ser como patrones' y hay gente de todo, hay boludos y hay algunos que no somos tan boludos. No me consideraba más viva pero tampoco la más boluda. Es decir, pero vamos, sos mi patrón ¿me vas a dar a mi este establecimiento para que yo lo labure, que yo? vamos, no podés ser tan boludo... ¿entendido? Hay algo que no va. Pero fueron convenciendo de tal manera a la gente que muchos de ellos sí, empezaron a hacer cooperativas ahí mismo, ahí adentro. 'Si porque Mellino les vende pescado', iqué pelotudos! Si yo soy tu patrón y veo lo que gana el tipo te vas a cagar para que te de mi empresa que me llevó años, no te la voy a regalar ¿Entendés?¿A cambio de qué? No, es mío ¿te parece? (...) Hubo luchas, hubo luchas, pero muy pocas, habíamos perdido mucha fuerza porque el SOIP no nos amparaba, el SOIP nos empujaba a las cooperativas. Nuestro sindicato se vendió" (María, filetera, 49 años).
\end{abstract}

Posteriormente, en el SOIP primó un paradigma de división obrera que excluía a los cooperativizados y también a los crecientes desocupados de la rama, impidiendo su afiliación. El desamparo gremial a los grupos obreros más castigados y precarizados -que anteriormente habían sido parte de las filas asalariadas- sumado a la falta de combate contra la patronal fresquera entre los años 1997 y 2000, terminaron por desatar un fuerte conflicto entre la conducción gremial y estos trabajadores, que culminó con el recambio de la dirigencia en 2002.

Un elemento trascendental para comprender esta disputa es un acontecimiento a nivel subjetivo: en el año 1997 muere Abdul Saravia, quien había sido dirigente del SOIP desde el año 1969 de forma ininterrumpida. De tradición peronista y con una política excesivamente personalista, este líder no pudo ser suplantado en su 
capacidad para influir sobre las bases obreras en la coyuntura conflictiva de la pesca durante los '90 (Colombo, 2014). Su muerte desencadenó un abrupto llamado a elecciones, en el que la conducción provisoria -de línea saravista- desaprobó la inclusión de las listas opositoras alegando que algunos de sus integrantes eran desocupados o cooperativizados.

Así, mientras transcurrían las reuniones multisectoriales y la disputa interburguesa, tras la muerte de Saravia desde marzo de 1997 se suceden de tres meses de conflicto ininterrumpido entre las listas y sus adherentes, con repudios, movilizaciones, presentaciones, golpes de puños y denuncias de fraude de ambos lados (Colombo, 2014). Este conflicto desembocó en la suspensión de los comicios, manteniéndose la dirigencia sindical bajo la figura de custodio de bienes y la política de alianza con el empresariado fresquero, pasiva ante la cooperativización, la desocupación y la precarización laboral en general de los trabajadores de la industria pesquera.

Sin embargo, el cuestionamiento hacia la dirigencia sindical llegó al punto de promover el surgimiento de nuevas organizaciones que agruparon a los obreros "desafiliados" del gremio, que nucleaban desocupados y cooperativizados. Entre ellas se destacaron la Unión Obrera del Pescado (UOP), la Unión de Trabajadores del Pescado y Afines (adherida a la Central de Trabajadores de la Argentina) y otra frustrada experiencia del Sindicato de Trabajadores del Pescado y Afines de la República Argentina (SIPES) impulsada por militantes gremiales comunistas con sede en el Sindicato de Luz y Fuerza de Mar del Plata (ambos adheridos a la CTA).

El crecimiento de estas organizaciones paralelas al SOIP significó el detrimento de la conducción sindical hasta su derrota, que previo a las elecciones oficiales tuvo su coronación en la toma del sindicato con la expulsión de la dirigencia. Esto ocurrió el 29 de junio 2000, un día después de un gran motín obrero contra los pulpos pesqueros que será abordado en el siguiente apartado. Cientos de obreros de la pesca que veían agudizadas sus condiciones de precarización laboral realizaron una asamblea en las calles portuarias. A raíz de la gran manifestación del día anterior el lugar estaba repleto de personal policial, de infantería y bomberos, quienes se hallaban custodiando la zona en vistas de contener la movilización obrera de un nuevo ataque a las empresas pesqueras. Entonces, un grupo de 300 trabajadores encabezados por la Unión Obrera del Pescado decidieron dirigirse hacia la sede del SOIP para exigirle que adhiera al paro que mantenían los marineros nucleados en el SOMU.

Al llegar al gremio desalojaron por la fuerza a los dirigentes y ocuparon el edificio, solicitando al Ministerio de Trabajo "que avale la comisión de base elegida en una asamblea y que convoque a elecciones dentro de 90 días" (Colombo, 2014: 443). Su programa reivindicativo incluía la registración de todos los trabajadores cooperativizados, la actualización salarial, garantía horaria y el dictado de una amnistía que permitiera la afiliación de todos los trabajadores que desarrollaban sus labores bajo el régimen de las cooperativas fraudulentas. Aquí se termina de definir una disputa entre la dirigencia peronista/saravista y los obreros cooperativizados y desocupados nucleados en su mayoría en la UOP. Algunos de ellos también eran militantes del Partido Obrero y ex militantes del Partido Comunista. Días después de la toma, la sede fue devuelta a su antigua conducción, pero el conflicto perduró y esta acción tuvo como saldo la consolidación de una nueva dirección obrera de parte de esta agrupación denominada "clasista", que dos años después como Lista Celeste ganaría la conducción del SOIP por la vía electoral. Esta victoria es resultado de una confluencia entre trabajadores desocupados, cooperativizados y asalariados registrados, quienes accedieron a incorporarse a la lista impulsada por la UOP en conjunto con "asesores" que formaban parte del grupo de trabajadores más precarizados, a fin de garantizar el cumplimiento del estatuto sindical vigente.

En síntesis, durante el período 1997-2002 la crisis del recurso merlucero que desencadenara la fuerte disputa interburguesa se imbricó con la crisis de representación gremial, de una dirigencia que se hallaba deslegitimada cuya condición caduca se agravó con la muerte de su histórico dirigente. Asimismo, las duras condiciones de trabajo y el desempleo agravado por la crisis pesquera, sumada a la crisis política y económica a nivel nacional y mundial, fue otro de los factores que provocaron la transformación en el SOIP. Asimismo, la conformación de agrupaciones de obreros cooperativizados y desocupados -que habían sido despedidos de las empresas y de su 
gremio- fue otro de los fundamentos para que la deslegitimación de la conducción saravista/peronista se tradujera en un cambio de dirigencia político sindical.

Posteriormente, la dilución del conflicto interburgués no eliminó la problemática de la falta de pescado, que de tiempo en tiempo provocaba momentos agudos de escasez que repercutían en los puestos de trabajo, tanto en su estabilidad como en su grado de precarización. El acuerdo interempresarial tampoco generó ningún cambio en la situación laboral de los trabajadores cooperativizados y temporarios.

De aquí que, ante la nueva coyuntura de la posconvertibilidad delimitada por el alza del precio del pescado, la caída de los salarios y la virtual recuperación del recurso pesquero, la nueva dirección del SOIP quiso impulsar en 2003 una huelga por tiempo indeterminado, aunando objetivos de lucha de los trabajadores en relación se dependencia y los cooperativizados: la recomposición salarial y la registración laboral. Esta huelga no cumplió sus objetivos y fue levantada a los pocos días por pedido de los propios afiliados, contribuyendo a la instauración de una nueva crisis al interior del gremio, basada fundamentalmente en una nueva propuesta de lucha. La nueva política gremial se define en un documento de divulgación de la línea dirigencial con estas líneas: "No se trata de reducir todo a la lucha en defensa del Convenio del 75 cuando hay compañeras y compañeros que sufren la tortura del trabajo en negro o de las cooperativas truchas, se trata de luchar cotidianamente en pos de lograr mejorar las condiciones de trabajo y de vida de miles de obreras y obreros del pescado" (Boletín Lista Celeste, 2006, p. 4). Esto significa que se misma trocaba la exigencia de la relación de dependencia y el ingreso de los trabajadores cooperativizados al CCT 161 por la implementación de convenios por empresa, política que se consolidó hacia el año 2007 cuando la dirigencia sindical apoyó el anexo al CCT del llamado Convenio Pyme. A través de este convenio entraron bajo relación de dependencia más de 1.000 trabajadores, pero el mismo fue sistemáticamente denunciado por algunos sectores movilizados de las cooperativas quienes lo consideraron "peor que estar en negro" (Colombo y Nieto, 2008). Entre algunos de los perjuicios para los trabajadores que promueve este Convenio se encuentra su carácter irrestricto para procesar cualquier producto marino apto para el consumo humano, independiente de su tamaño; esto es perjudicial para el obrero porque las especies más chicas ocasionan más esfuerzo y tiempo de trabajo, haciendo necesario procesar más cantidad de pescado para obtener ingresos similares que antaño. Por otra parte, basándose en las "características y exigencias de la actividad pesquera" y la influencia de las posibilidades de captura, condiciones meteorológicas y demás circunstancias "que no dependen de la voluntad del empresario", se efectiviza la implementación de una "jornada especial de trabajo" con una movilidad y flexibilidad que permite al empresariado fijar un horario de trabajo "elástico" pudiendo añadir dos horas antes y después del horario preestablecido, contando con una extensión semanal de 44 horas de trabajo(Resolución 584/2007 de la Secretaría de Trabajo de la Provincia de Buenos Aires). Por ello, el Convenio Pyme no solo mantiene la inestabilidad laboral y la superexplotación, sino que otorga una nueva legalidad que ampara al empresario y precariza al trabajador.

La lucha sindical por la obtención del Convenio Pyme generó nuevas disputas intrasindicales que se tradujeron en diversas acciones conflictivas, tales como piquetes, nuevas tomas de la sede sindical, enfrentamientos con la prefectura e inclusive peleas entre trabajadores.

Haciendo un paréntesis en la dimensión temporal, cabe destacar que, previamente al año 2007, se sucedieron numerosos conflictos en el marco de las luchas por la recomposición salarial características de los primeros tiempos de la posconvertibilidad (Piva, 2016). Pero estos conflictos fueron cediendo paso a la re-emergencia de las luchas por la registración laboral en momentos en los que resurgía la escasez de materia prima, lo cual golpea rápidamente a los trabajadores más precarizados.

Retomando el marco de la lucha por los convenios de registración por empresa, la reciente conducción "clasista" fue acusada de burócrata, generándose así un nuevo conflicto por la conducción del gremio que se tradujo en sucesivas rupturas y reagrupamientos de la que fuera la originaria Lista Celeste. El cambio en los objetivos de lucha, que se redujeron sustancialmente luego de que referentes de la UOP, el Partido Obrero y el Partido Comunista ingresen en la conducción gremial, provocó conflictos y divisiones internas: en el año 2004 la Lista 
Celeste se escindió, quedando fuera de ella y del sindicato militantes del Partido Obrero; en las elecciones de 2006 se presentaron dos listas que provenían de la originaria Celeste, obteniendo la victoria la que contenía integrantes de la UOP y el PC que reconocían tradiciones más peronistas que clasistas. En el año 2004, los militantes del Partido Obrero que se separaron de la comisión directiva conformaron la Lista Bordó. Luego, en el año 2010 se vuelve a dividir la conducción celeste y gana una de las listas resultantes de ese fraccionamiento, la lista Negra y Blanco con Cristina Ledesma a la cabeza, quien conduce el sindicato hasta la actualidad. $\underline{\underline{ }}$

Finalizando el recorrido por la órbita sindical, en abril el año 2011 el SOIP inició una huelga por 72 horas con el objetivo del incremento salarial del 35\%.La medida incluyó movilizaciones y un bloqueo de todos los accesos al puerto local que se mantuvo durante varios días, lo que provocó desabastecimiento de pescado en los principales mercados bonaerenses además de restringir las exportaciones. A raíz de ello, el Ministerio de Trabajo dictó la conciliación obligatoria y amenazó con el quite de personería jurídica del SOIP, pero el sindicato hizo caso omiso y persistió con las medidas. $\underline{8}$

Al acercarse la fecha de Semana Santa, la cuantiosa ganancia empresarial prevista durante esos días aceleró la resolución del conflicto con una propuesta de aumento salarial del 30\%, que fue aceptada por el gremio. Sin embargo, volvió a quedar pendiente la demanda de los más precarizados de la rama, quienes protagonizaron nuevos hechos de conflictividad a nivel fabril que describiremos en el último apartado.

En el caso necochense, la disputa en el plano sindical se analizará en base a los casos de empresas recuperadas. El Sindicato de la Alimentación es el gremio que nucleó a los trabajadores de la industria pesquera de Necochea, cuya política fue la de un gran apoyo al primer proceso de recuperación local -el caso de la firma Industrial Pesquera- mientras que unos meses más tarde se comportó con total indiferencia ante la segunda recuperación emprendida por los trabajadores de Engraulis.

En ambos procesos los agrupamientos obreros que emprendieron la recuperación y la ocupación de las empresas tenían en sus filas a delegados sindicales, por lo que existía un vínculo previo entre estos referentes obreros y los dirigentes gremiales. También en los dos casos el gremio fue parte activa de muchas de las acciones conflictivas contra los despidos y los cierres por quiebra. Pero tras el retiro de los empresarios, el sindicato tomó caminos opuestos.

La conducción sindical del STIA desde 2010 hasta 2013 tuvo como secretario general a Juan Pablo Moreno, de alineación peronista. El y Guillermo Daniel, abogado gremial, fueron los que formaron parte de las acciones conflictivas obreras en ambos procesos de recuperación, con la diferencia de que en el caso de La Recuperada continuaron haciéndose presentes en la planta procesadora, colaboraron con recursos materiales para los trabajadores (cajas de alimentos, donaciones para festivales), y brindando representación legal a los trabajadores en el juicio por la quiebra y el pedido de expropiación durante todo el desarrollo de la causa, que prosigue hasta la actualidad. Los trabajadores de La Recuperada mantienen una representación paternalista del sindicato, que según ellos "actuó como un padre como con un hijo"- , acompañando y apoyando al colectivo obrero en la reactivación de la unidad productiva. En el caso de Engraucoop, de acuerdo a los trabajadores el vínculo con la dirigencia gremial finalizó tiempo después de la consumación de los despidos, generando una fuerte enemistad desde los obreros y una pérdida de la referencia sindical. Por ello, mientras que los trabajadores de La Recuperada (exIndustrial Pesquera) asiduamente elogian el accionar sindical en su lucha por la autogestión obrera y recalcan que "el sindicato se portó muy bien", $\underline{10}$ las obreras de Engraucoop dicen de los mismos dirigentes frases como "quedamos en la calle y se olvidaron de nosotras". 11

Asimismo, los trabajadores de La Recuperada recalcan que la idea de recuperar la empresa con una cooperativa fue propuesta por el sindicato. El grupo obrero llevó a cabo la cooperativización luego de haber sido convencido por la dirigencia sindical de su viabilidad y también de su diferencia con respecto al trabajo en una cooperativa fraudulenta. Solo después de ello los trabajadores transformaron conceptualmente la ocupación de la planta procesadora en recuperación de la fábrica bajo gestión obrera, a pesar de haber previamente materializado una 
actividad autogestivapor sus propios medios, sin conocer otros casos, con el único objetivo de "sobrevivir" mediante su trabajo. En Engraulis, en cambio, el sindicato comenzó representando al colectivo laboral ante la quiebra, pero luego renunció a desempeñar este rol.

Al entrevistar al abogado gremial, Ernesto Daniel, hallamos que el motivo de la discontinuidad sindical en este proceso se debió a un "conflicto de intereses" entre los mismos trabajadores: un grupo de ellos quería recuperar la empresa mientras que el resto prefería que se proceda lo más rápidamente posible a la subasta de los bienes empresariales a fin de cobrar sus indemnizaciones. Por este motivo, el segundo grupo se oponía a la consecución de la ocupación y continuación de la producción, entrando en abierta confrontación legal y material con el primer grupo, que luchaba por la continuidad autogestiva inmediata. La posición del gremio en este conflicto fue retirarse de la situación, desvinculándose del conjunto de ex-empleados de Engraulis.

\section{La disputa de clases}

Al imponer el régimen de las cooperativas fraudulentas a más de la mitad de los trabajadores de la industria pesquera, el empresariado buscó no solo disciplinar a los asalariados incrementando la explotación y la opresión, sino también dividir las filas obreras. De esta forma, los empresarios no solo redujeron derechos laborales, sino también intentaron subyugar las luchas de los trabajadores registrados, en quienes la amenaza de desocupación, cooperativización o trabajo en negro se ve acrecentada con la escasez del recurso.

Para analizar la disputa capital-trabajo en el caso marplatense-que abarca un largo período- nos centraremos en los grandes conflictos, denominados como "estallidos sociales" por Nieto y Colombo (2008), en cuya órbita ubicaremos conflictos precedentes y consecutivos. En este sentido podemos ubicar la emergencia de tres importantes acciones conflictivas obreras contra el capital en los años 2000, 2007 y 2011.

La falta de materia prima es uno de los rasgos que atraviesa en mayor o menor medida todo el período estudiado. Uno de sus principales impactos en la fuerza de trabajo es la reducción inmediata de los puestos laborales requeridos por los empresarios, dejando temporariamente desempleados a los trabajadores eventuales y cooperativizados. La situación para este grupo de obreros se vuelve desesperante en pocos días, lo cual motiva formatos de protesta variados que, si transcurre el tiempo y no obtienen una respuesta favorable, ven acrecentada su necesidad y bronca. A causa de ello, si bien los asalariados registrados en todo el período realizaron numerosas huelgas a fin de obtener una recomposición salarial, los trabajadores no registrados de la rama fueron los protagonistas de las acciones más disruptivas y con mayor grado de implicancia física, y por ello los sujetos clave de estos estallidos sociales (Nieto, 2010).

Retomando el conflicto iniciado en Mar del Plata en el año 1997 a raíz de la crisis de la merluza, el conjunto de los trabajadores en un primer momento compartió las demandas del empresariado fresquero, pero continuamente agregaron otras referidas a las condiciones de trabajo y de contratación. Tanto desocupados como los temporarios y cooperativizados solicitaban el ingreso de pescado y también la expulsión de los buques congeladores del puerto como paso previo para tener oportunidades laborales, exigiendo luego subsidios para desocupados, contrato en relación de dependencia para temporarios y cooperativizados y también denunciando a las cooperativas fraudulentas. Sin embargo, las reivindicaciones propiamente obreras nunca llegan a ser abordadas por la multisectorial, por ello fue rasgo general del período que, al regreso de cada movilización a Buenos Aires realizada de forma conjunta por todos los integrantes de la multisectorial, los obreros se movilizaban por su propia cuenta ante la falta de respuesta ante los propios reclamos. De esta forma volvía a emerger de tiempo en tiempola disputa capital/trabajo, que quedaba temporalmente sumergida en la disputa interburguesa.

Sin embargo, la división obrera entre asalariados registrados y no registrados también se hizo palpable en las acciones realizadas en forma separada, al centrarse cada grupo en distintos objetivos que no estaban aunados en la lucha gremial. 
En un primer ciclo de protesta que puede ubicarse entre 1997-2002 el grupo de trabajadores más precarizados es el que realiza mayor cantidad y variedad de acciones, entre las que resaltan los cortes de calle, ollas populares y asambleas, instalación de carpas, tomas de la Delegación Municipal del Puerto y de otras dependencias gubernamentales(Colombo y Nieto, 2008).

En el año 1999, por ejemplo, a la vuelta de la movilización en Buenos Aires con la obtención de la promesa por una Ley de emergencia pesquera por parte del Ejecutivo nacional, desde la multisectorial se instó a los trabajadores a retomar las tareas. Sin embargo, los obreros se reúnen en asambleas sin participación de las dirigencias gremiales y deciden realizar un paro hasta la sanción definitiva de la ley. Esta medida de fuerza se mantiene hasta el 23 de junio, día en que el presidente Menem le dio su aprobación definitiva. Pero aquí retomaron las tareas los trabajadores asalariados registrados y de planta permanente, mientras que temporarios, cooperativizados y desocupados continuaban sin trabajo; por ello una fracción lanza un plan de lucha con ollas populares y movilizaciones por un subsidio de 500 pesos. Finalmente, este subsidio se obtuvo, pero no así el pase a planta permanente ni el "blanqueo".

En el año 2000 la presidencia de De la Rúa continuó con la aplicación de la emergencia pesquera y con los subsidios a los desocupados, pero la escasez del recurso volvió a tensar la situación hasta que el 12 de mayo todos los gremios a excepción del SOIP convocaron a un paro de actividades debido a la falta de respuesta empresarial a sus reclamos. La tensión continuó hasta el 27 de junio, día en que se declararon en huelga todos los gremios pesqueros. Al día siguiente se produjo un gran estallido social de los obreros de la pesca, quienes atacaron la sede de la CAABPA y tomaron delegaciones municipales. Esta manifestación cobró rasgos espontáneos, ya que se produjo luego de una asamblea en el puerto integrada por trabajadores tanto marineros como fileteros, en la que estuvieron ausentes los representantes gremiales. Los trabajadores se movilizaron y atacaron 6 plantas pesqueras propiedad de los grandes grupos económicos pesqueros, en un motín que se perduró por un lapso de dos horas durante las cuales los obreros fueron reprimidos por la policía con gases lacrimógenos y balas de goma (Colombo y Nieto, 2008). Al día siguiente se produjo la movilización y toma de la sede sindical, descripta en el apartado anterior. De allí que uno de los principales resultados de este ciclo de conflictos en torno al estallido social del año 2000 es la catálisis de la Lista Celeste que luego gana las elecciones gremiales en el año 2002.

Aquí podemos ver cómo el campo de disputa interburgués se entrecruza con el sindical y el conflicto de clases, ya que producto de la derrota de la lucha obrera en el conflicto capital/trabajo que transcurría a la par de la cruda pulseada interburguesa, un grupo organizado de trabajadores emprende una lucha contra la conducción sindical y finalmente logra expulsar a esa dirigencia, ubicada en el lugar de responsable de la derrota contra el capital.

Seguidamente, la devaluación y la recuperación del recurso pesquero pospusieron la crisis que afectó a la industria pesquera entre los años 1997-2002. Los stocks de pescado fueron recobrándose en forma parcial, permitiendo al empresariado reducir las pérdidas producto de la sobrecapitalización anterior al aumentar el precio internacional de los productos pesqueros de exportación. Pero desde la perspectiva obrera, el nuevo ciclo iniciado en 2002 caracterizado por la devaluación provocó la depreciación de la fuerza de trabajo, dada por la reducción de los salarios. Por ello la puja entre clases desde 2002 se basó mayormente en la lucha obrera por la recomposición salarial, con la huelga como principal método y acción. Por su parte, las acciones conflictivas protagonizadas por cooperativizados y desocupados no desaparecieron, aunque decayó su número y prominencia (Colombo y Nieto, 2008).

Llegado el año 2007 resurgió el problema de la escasez que agudizó nuevamente la situación de los cooperativizados. La falta de trabajo y su precarización provocó nuevamente la lucha de este grupo obrero, cuyos motivos residían preponderantemente en la actualización salarial y la registración laboral con el convenio 161/75. De esta forma resurgieron los piquetes en el puerto, ollas populares, asambleas, retenciones de tareas en los lugares de trabajo, tomas del Ministerio de Trabajo, del Concejo deliberante y del Palacio Municipal, ataques a plantas procesadoras y a las sedes de las Cámaras Pesqueras con represión y enfrentamiento con las fuerzas policiales. También se produjo una nueva toma del sindicato y expulsión de la dirigencia. El convenio Pyme 
resultante descomprimió momentáneamente la situación, pero sus efectos -como vimos anteriormente- fueron escasos en cuanto a la precarización laboral, no solo para los obreros incluidos en dicho convenio sino también para tantos otros que quedaron fuera del mismo. Por ello esta nueva disputa de clases impactó nuevamente en el plano intrasindical, lo cual observamos en el anterior apartado en las sucesivas rupturas en las listas y los partidos políticos vinculados al SOIP luego de 2002.

En cuanto a la crisis que tuvo como epicentro el año 2011, desde fines de febrero de ese año comenzó a manifestarse una álgida conflictividad que duró meses e implicó varias huelgas consecutivas. Uno de los primeros hechos partió de los cooperativizados con el reiterado reclamo de registración laboral en dos plantas a la vez. En una de ellas -llamada Romano- los trabajadores realizaron una toma y se declararon en asamblea permanente, mientras que en la otra -Frigosur- armaron una carpa frente a la empresa con retención de tareas. $\underline{12}$

Tal como se describió en el apartado anterior, en el mes de abril el SOIP realizó un paro total de actividades contra la Cámara Industrial Pesquera Argentina, nucleando las demandas de aumento salarial para los obreros en relación de dependencia y de registración laboral para los trabajadores cooperativizados. Sin embargo, el conflicto nuevamente cesó al obtenerse el aumento salarial. $\underline{13}$

Luego, en el mes de junio, por atrasos salariales y deudas de la firma Barilari, los 8 gremios que involucraban a la masa obrera que allí se desempeñaba se declararon en estado de alerta, paro y movilización, ocupando la fábrica y paralizando la flota de camiones. En esta oportunidad se nuclearon en una acción conjunta el SOIP y el SOMU con el Sindicato de Conductores Navales de la República Argentina (Siconara), el Sindicato Marítimo de Pescadores (Simape), el Sindicato de Empleados de Comercio (SEC), el Sindicato de Choferes de Camiones, el Sindicato Argentino de Obreros Navales (SAON) y Asociación Argentina de Capitanes, Pilotos y Patrones de Pesca.

La toma se extendió a otras plantas, como las del grupo Solimeno, llegando a abarcar 15 establecimientos durante ese mes. También se produjeron ataques y escraches tanto a las unidades productivas como a los domicilios de los propietarios, agregándose como acción conflictiva el secuestro del padre del empresario Salvatore como presión para que éste acuda a negociar con los obreros $\underline{14}$.

El carácter irresoluto de las principales demandas obreras contra el capital ha provocado que estos escenarios no dejen de repetirse en la industria pesquera marplatense, reapareciendo sujetos, organizaciones y formas de lucha. Por ello la actualización salarial y la registración laboral continúan siendo los pivotes que configuran la conflictividad obrera en esta localización portuaria, en un contexto signado por la precarización e inestabilidad con un constante riesgo de desocupación.

En la ciudad de Necochea, los más actuales y notorios hechos de conflictividad sociolaboral en la industria pesquera corresponden a los dos procesos de recuperación de empresas bajo gestión obrera que se sucedieron en 2011 y 2012. En estos conflictos, la burguesía se desligó de palabra y de hecho de la responsabilidad por los despidos obreros tras la crisis y quiebra, ingresando en la vía judicial (Nogueira, 2012 y 2014).

Tanto la ex Industrial Pesquera como la ex Engraulis -firmas que desembocaron en las ERT La Recuperada y Engraucoop, respectivamente- desarrollaban actividades de procesado y venta en los mercados externo e interno en Necochea desde la década del ' 70 . Mientras que la primera se dedicaba a la producción fresquera (lenguado y raya en mayor medida) y sus propietarios eran argentinos, la segunda realizaba conservas de anchoas y sus capitales eran extranjeros.

Industrial Pesquera contaba con 27 asalariados efectivos en 2011, mientras que en Engraulis se desempeñaban 60 obreros. El personal temporario igualaba al estable en ambas empresas durante los períodos en los que el volumen de materia prima superaba la capacidad productiva de la fuerza de trabajo permanente. En Industrial Pesquera predominaban los trabajadores de género masculino, mientras que en Engraucoop el $90 \%$ eran mujeres. Esta diferencia se asienta en la histórica división del trabajo en la industria pesquera, por la cual el personal ocupado en 
el sector conservero fue predominantemente femenino mientras que en el sector fresquero sucede a la inversa, prevaleciendo la fuerza de trabajo masculina. ${ }^{15} \mathrm{Al}$ respecto, aún estamos indagando el vínculo entre esta diferenciación basada en el género de la composición obrera y la posterior configuración de los dos casos de recuperación.

Entre los años 2010 y 2012, ante el anuncio de quiebra y cierre de estas plantas pesqueras los obreros emprendieron una serie de acciones tendientes a preservar su fuente laboral, que se tradujeron en diversos hechos de conflictividad social (Nogueira y Schulze, 2016). En la ciudad la tradición de lucha enmarcada en procesos de recuperación era prácticamente nula, de aquí que cobra importancia el hecho de que el primer proceso fuese impulsado no solamente por trabajadores sino también por una organización política que actuó en conjunto con la dirigencia local del Sindicato de la Alimentación. Creemos que, sin la participación de estos actores como motores de la autogestión, la misma no hubiera sido posible. Asimismo, consideramos que el primer conflicto marcó y determinó la consecución del segundo.

Como sucede en la mayoría de los casos de empresas recuperadas, el proceso conflictual en Industrial Pesquera inició a raíz de la parálisis de la unidad productiva, falta de pago de los salarios y desabastecimiento de materia prima. En sus primeras acciones los obreros tuvieron como objetivos la reactivación del trabajo y el pago de los salarios adeudados, y con el tiempo, ante la falta de respuestas y finalmente el anuncio de la quiebra, la lucha cobró el carácter de una recuperación. En ese lapso, militantes de una organización política integrante del Frente Popular Darío Santillán-llamada Cruz del Sur- comenzaron a reunirse en la fábrica junto con los obreros y el Sindicato de la alimentación, transmitiendo experiencias de recuperación tales como la de Zanón y el Hotel Bauen. Esta propuesta tuvo apoyo desde el sindicato, y pronto los trabajadores la vieron como su única salida para conservar sus fuentes laborales. La lucha y resistenciaque inició en diciembre de 2010 para mayo del año siguiente decantó en la conformación de la Coooperativa "La Recuperada", por parte de un grupo de trabajadores. Los tipos de acciones conflictivas dentro de este proceso fueron la toma de lugar de trabajo, cortes de calle, manifestaciones, comunicados de prensa, actividades artísticas y festivales, huelgas, reuniones entre las partes y ocupación de edificios públicos.

Además de los trabajadores, el Sindicato y Cruz del Sur, docentes y estudiantes de la carrera Terciaria de Trabajo social participaron de muchas acciones, así como dirigentes gremiales de Corriente Nacional del Sindicalismo Peronista, artistas y funcionarios gubernamentales. Los reclamos obreros consiguieron un amplio marco de apoyo a nivel político y social, materializándose en el pronunciamiento a favor por unanimidad del Concejo Deliberante local hacia el pedido de expropiación de la unidad productiva y en la masiva concurrencia a peñas, festivales y acciones de lucha en las calles.

Cabe destacar que en ambas recuperaciones la mayoría de los hechos y la posterior conformación de la cooperativa de trabajo fueron realizadas por un grupo reducido de obreros en relación con la totalidad de los trabajadores de ambas plantas procesadoras. En el caso de La recuperada solo 8 obreros de los más de 50 entre efectivos y temporarios fueron los que llevaron adelante las acciones.

En el caso de Engraucoop el proceso de recuperación se presentó en dos tiempos. El primer período ocurrió entre mayo y julio de 2010 y tuvo como desencadenante el anuncio y luego la concreción de una importante reducción de personal. En ese momento los trabajadores ocuparon la unidad productiva durante un mes, además de realizar manifestaciones y concurrir a reuniones entre partes en la sede local del Ministerio de Trabajo. En la última reunión de julio de 2010 se determinaron retiros voluntarios y la reactivación parcial de la planta para realizar algunos pedidos puntuales. El segundo período lo ubicamos un año después, en agosto de 2011, cuando se produce una nueva toma del lugar de trabajo. La medida surge al anunciarse el ingreso a concurso de acreedores como antesala de la quiebra empresarial, junto a lo cual los propietarios refirieron que no abonarían ni los últimos salarios ni las indemnizaciones de los trabajadores por falta de activos líquidos.

Sin embargo, mientras que en el caso de la Recuperada se logró una importante repercusión social con apoyos públicos sociales y políticos, en Engraucoop solo puede ubicarse al STIA como participante del proceso de la 
recuperación además de los trabajadores. No obstante, este involucramiento se limitó -como vimos- al período inicial.

Una de las obreras relata que, con posterioridad al retiro patronal, estuvieron varios meses trabajando en la producción de pedidos puntuales que habían quedado pendientes de entrega por la firma anterior $\frac{16}{}$, lo que muestra algo similar al caso de Industrial Pesquera, es decir, una gestión obrera de hecho sin que se hubiese enunciado aún como empresa recuperada. En una recorrida por dependencias municipales durante una mañana de enero de 2012 en busca de alimentos y otros subsidios, un fortuito encuentro con dos funcionarios locales los contactaron con el INAES, lo cual fue el puntapié del inicio de las acciones legales que derivarían en la conformación de la cooperativa de trabajo $\frac{17}{}$. Si bien las trabajadoras refieren que conocían el proceso de la Recuperada y sabían que la autogestión era un camino posible, no lograban su concreción por desconocer las vías institucionales, dificultándose la obtención de materia prima y de compradores de la producción.

A diferencia de la primera recuperación, los trabajadores -en su mayoría mujeres- continuaron en soledad la ocupación de su lugar de trabajo y el reanudamiento de la producción, con la particularidad de que se constituyeron dos grupos obreros, de los cuales uno quería preservar los puestos de trabajo y otro continuar exigiendo las indemnizaciones. Ambos grupos entraron en confrontación mientras confluían en la fábrica para producir los pedidos pendientes con la materia prima que había quedado allí, hasta que finalmente el segundo agrupamiento se retiró del lugar de trabajo y continuó la lucha en el plano legal a través del juzgado civil. $\underline{18}$

Cabe destacar que tanto en La Recuperada como en Engraucoop las tomas de los lugares de trabajo son las únicas acciones que se prosiguieron en el tiempo, en un primer momento con la finalidad de regularizar la situación laboral y luego como parte de la lucha por la recuperación de la empresa bajo gestión obrera. De las tres ocupaciones, la primera se extendió por un mes y las dos restantes se continuaron luego bajo la forma de constitución de las empresas recuperadas. Las ocupaciones, entonces, pueden ubicarse como las acciones transversales de estos conflictos, a las que se superponen otras formas de rebelión transitorias que van desde las manifestaciones en la vía pública hasta las reuniones entre partes; estas últimas predominan hacia el final del período conflictual. Sin embargo, cabe señalar el carácter irresoluto de estos procesos, lo que impide definir en sentido estricto su finalización. Las ocupaciones prosiguen y la conservación de las fuentes de trabajo no guarda estabilidad sino importantes dificultades de subsistencia, continuidad productiva y rentabilidad. Por ello, la conformación de la cooperativa de trabajo con el correlato de la recuperación de la empresa bajo gestión obrera no significa aquí la terminación del conflicto sino un momento particular del mismo, en el que el sujeto patronal se desdibuja y aparenta desaparecer, aunque sigue estando presente en las acciones judiciales correspondientes a la quiebra y los juicios laborales.

En el caso de Necochea vemos entonces que el desmantelamiento progresivo de los establecimientos producto de la concentración empresarial, sumado a la falta de otras industrias alimenticias de importancia en la ciudad, generó a la vez un debilitamiento sindical. El rol cumplido en las últimas décadas por parte del gremio fue la negociación de las indemnizaciones por los despidos producto del desguace del enclave industrial, situación que se temía inviable en los dos procesos de recuperación. En ambos, los empresarios refirieron que no pagarían las indemnizaciones por no disponer de capital monetario, a diferencia de la última planta que cerró en 2012 (Incoop), en la que se negociaron los despidos abonando la empresa el $100 \%$ de las indemnizaciones. $\frac{19}{}$ Este diferente desenlace puede pensarse como explicación de la disímil actuación gremial que apoyó los procesos de lucha obreros en los lugares de trabajo, pero además de este factor cabe destacar la importancia del vínculo previo entre el delegado de la planta de Industrial Pesquera y la dirigencia gremial como otro factor influyente en estos procesos. Hipotetizamos que este vínculo actuó impulsando el involucramiento sindical en la prosecución de la lucha autogestiva, que de otra manera hubiese tomado la vía hegemónica de negociación de indemnizaciones en cada vez más largas, arduas e infructuosas disputas jurídicas, en las que la patronal no tiene nada que perder.

Con el correr de las décadas, se estima que fueron 3.000 los puestos de trabajo perdidos en la industria pesquera entre los 1980 y 2012 (Nogueira, 2017), situación que generó exilios obreros, incremento de la desocupación tanto 
en la localidad como en pequeñas ciudades cercanas (tal es el caso de Lobería, de donde diariamente llegaban micros repletos de fileteros a desempeñarse en plantas necochenses) y reconversión obrera en otros sectores a nivel local, como el de la construcción y los servicios de transporte.

\section{Conclusiones}

Luego del análisis de estos tres campos de disputa, consideramos haber obtenido una descripción densa de la complejidad de las órbitas de las constelaciones conflictivas de la industria pesquera bonaerense de las ciudades portuarias Mar del Plata y Necochea. Una descripción que no es acabada, sino que se presenta como puntapié para continuar indagando al respecto.

La interpenetración de estos campos es fundamental para la comprensión de la conflictividad sociolaboral del período, lo cual posibilita analizar cómo las acciones de lucha obrera en torno al conflicto generado por la crisis del recurso pesquero se imbrican con la crisis económica interempresarial y la crisis de representación gremial.

Por un lado, la disputa interburguesa continúa vigente en forma latente y silenciosa, dada la configuración del mercado mundial que actúa determinando ciertos límites para las pequeñas y medianas empresas e impulsando a los grandes grupos económicos a una mayor concentración y monopolización. En este sentido, si bien actualmente no se expresan abiertamente grandes conflictos interempresariales, persiste la tendencia al acrecentamiento de la brecha entre empresas grandes y pequeñas, llevando a estas últimas al límite marcado por el cierre por quiebra o la absorción.

En el plano sindical, en la ciudad de Necochea este campo es prácticamente inexistente dado el desmantelamiento de la actividad y la reducción drástica de los trabajadores en relación de dependencia. En la ciudad de Mar del Plata, el recambio en la conducción sindical no guardó consolidación sino nuevas crisis, aunque acrecentó niveles de participación en determinadas medidas y contextos de lucha. A pesar de agrandar su campo de representación incluyéndolas demandas de los trabajadores no registrados, aun no pudo incidir fuertemente en la dualización de la fuerza de trabajo que afecta a la rama; en este sentido sigue primando la división entre "trabajadores de primera" y "trabajadores de segunda" en cuando a las diferentes condiciones de trabajo y de contratación, distintos niveles de inestabilidad laboral y, por ende, de explotación y opresión por parte de la patronal. Asimismo, ambos grupos obreros guardan diversas posibilidades y límites de lucha, que en numerosas ocasiones lleva al sector más precarizado a callejones sin salida. Esto se vincula, en parte, con la continuidad en la diferenciación en cuanto a la posibilidad o no de afiliación en el SOIP, que no ha modificado el estatuto y solo permite la afiliación de trabajadores registrados.

En cuanto a la disputa de clases, en ambas ciudades portuarias se destaca el carácter irresoluto de la conflictividad acontecida en los quince años abordados.

En Necochea, el formato de protesta de la recuperación de las empresas guarda estrecho vínculo con el desmantelamiento del sector empresarial, dado que la desaparición del actor patronal inhabilita otras medidas de lucha contra el desempleo. Asimismo, los procesos de recuperación no proporcionan estabilidad ni ingresos acordes al salario mínimo, vital y móvil que permitan a los trabajadores asegurar su subsistencia y la de sus familias. Por otra parte, las causas de las quiebras de las firmas Industrial Pesquera y Engraulis continúan abiertas, con riesgo de materializarse la subasta de los inmuebles y otros bienes empresariales, a desmedro de las empresas de gestión obrera, como así también de las indemnizaciones adeudadas a la totalidad de los trabajadores.

En Mar del Plata, los cambios en las conducciones sindicales y en los convenios de contratación vigentes no han solucionado los problemas de fondo signados por la inestabilidad, la superexplotación, la precarización laboral y el riesgo de desocupación. La diversidad de las formas de lucha y el grado de radicalización que han alcanzado avizoran nuevos horizontes de protesta obrera.

La superposición de las órbitas que configuran las constelaciones de la conflictiva industria pesquera bonaerense 
expresa sus múltiples anudamientos y su complejidad propia. Esperamos, en el camino de la búsqueda de comprensión profunda de los procesos históricos y subjetivos abordados, haber aportado algunos elementos de análisis al respecto.

\section{Fuentes de la prensa gráfica}

-Ecos Diarios, Necochea.

-La Capital, Mar del Plata.

\section{Entrevistas}

-Entrevista grupal a La Recuperada, realizada por la autora el 24 de octubre de 2011.

-Entrevista a Mario, 56 años, filetero en La Recuperada, realizada por la autora el 27 de octubre de 2011.

-Entrevista a Julián, 29 años, filetero en la Recuperada, realizada por la autora el 30 de octubre de 2011.

-Entrevista grupal a La Recuperada, realizada por la autora el 18 de octubre de 2013.

-Entrevista grupal a La Recuperada, realizada por la autora el 25 de abril de 2014.

-Entrevista a Darío, 34 años, filetero en La Recuperada y ex delegado sindical, realizada por la autora el 25 de abril de 2014.

-Entrevista a Natalia, 37 años, filetera en La Recuperada, realizada por la autora el 28 de abril de 2014.

-Entrevista a Mario, 58 años, filetero en La Recuperada, realizada por la autora el 15 de febrero de 2015.

-Entrevista grupal a Engraucoop, realizada por la autora el 8 de octubre de 2012.

-Entrevista grupal a Engraucoop, realizada por la autora el 22 de octubre de 2013.

-Entrevista a Roque, 45 años, pescadero y propietario de embarcación, realizada por la autora el 19 de febrero de 2015.

-Entrevista a Guillermo, 42 años, abogado del STyA sede Necochea, realizada por la autora el 4 de abril de 2017.

-Entrevista a Nancy, de 54 años, desempleada, trabajadora en el área pesquera desde 1976 hasta 2007, militante del Partido Obrero, realizada por Estefanía Martynowskyj el 18 de mayo 2009, en el marco de un trabajo práctico aplicado de Investigación cualitativa dirigido por la docente Alejandra Navarro en la materia "Metodología cualitativa" correspondiente a la carrera de Sociología de la UNMdP.

-Entrevista a Marta, 49 años, trabajadora manual del puerto, realizada por Maia Morgenstern el 15 de mayo 2009 , en el marco de un trabajo práctico aplicado de Investigación cualitativa dirigido por la docente Alejandra Navarro en la materia "Metodología cualitativa" correspondiente a la carrera de Sociología de la UNMdP.

-Entrevista a Eduardo, filetero, 60 años, realizada por Martina Castro el 14 de mayo de 2009, en el marco de un trabajo práctico aplicado de Investigación cualitativa dirigido por la docente Alejandra Navarro en la materia "Metodología cualitativa" correspondiente a la carrera de Sociología de la UNMdP. 


\section{Notas}

1 El Plan de Tesis se titula: "Entre la precarización laboral y la autogestión obrera: Estrategias laborales y subjetividades inherentes a las trabajadoras y los trabajadores de la industria pesquera de Mar del Plata y Necochea-Quequén (1997-2012)”.

$\underline{2}$ En relación a la protesta obrera en el sector industrial pesquero a nivel internacional en las últimas décadas, se observa una vacancia investigativa importante. Sin embargo, podemos encontrar trabajos como el de Santiago Aguiar, que aborda el caso de un largo conflicto de trabajadores de la industria salmonera en Chile acontecido en el mismo período estudiado, en la cual se reitera la lucha de trabajadores precarizados en un sector económico en franco crecimiento entre los 1990 y 2008, en el marco de un contexto de crisis y despidos masivos (Aguiar, 2009).

$\underline{3}$ Conjunto de estrellas que, mediante trazos imaginarios, forman un dibujo que evoca una figura determinada (Diccionario de la RAE).

4 El Seminario de Investigación sobre el Movimiento de la Sociedad (SISMOS) es un proyecto de investigación integrado por investigadores y estudiantes de diversas disciplinas sociales y humanísticas de las ciudades Mar del Plata, Bahía Blanca y Necochea. Este grupo, dirigido por el Dr. Agustín Nieto, diseñó un modelo de carga de acciones de conflictividad social con el objetivo de confeccionar -posteriormente- una base de datos que permita identificar, contabilizar, describir y realizar análisis cuantitativos y cualitativos de estos hechos de rebelión. Tiene como fin "procurar un minucioso y concienzudo (pero no infalible) seguimiento de la conflictividad social local" (SISMOS, Manual de carga, versión 2014).

$\underline{5}$ Censo Nacional Pesquero, INIDEP, 1996.

6 Diario La Capital, edición del día, 11/05/2000.

7 Revista Puerto, octubre de 2010.

8 Diario La Capital, edición del día 12 de abril de 2011.

9 Entrevista a Mario, filetero de La Recuperada, febrero de 2014.

10 Entrevista grupal a la Recuperada, octubre de 2011.

11 Entrevista grupal a Engraucoop, octubre de 2013.

12 Revista Puerto, marzo de 2011.

13 Diario Cadena3.com, edición del día 19 de abril de 2011, www.cadena3.com/contenido/2011/04/18/74454.asp , consultado por última vez el 14 de marzo de 2017.

14 Agencia Nova, edición del día 15 de junio de 2011, www.agencianova.com/nota.asp?

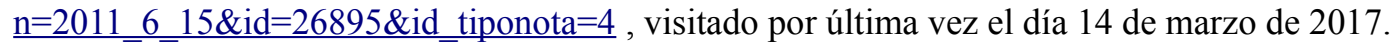

15 Sobre los motivos históricos y culturales de esta división del trabajo basada en el género, ver Lanari y Cutuli, 2010 .

16 Entrevista grupal a Engraucoop, octubre de 2012.

17 Entrevista grupal a Engraucoop, octubre de 2012.

18 Causa“Engraulis s/quiebra”NNo 3574-7011,expNo 37489 .

19 Ecos Diarios, edición del día 5 de febrero de 2012. 


\section{Bibliografía}

Aguiar, S. (2009). "El caso de la huelga larga de los trabajadores del salmón en Chile. Estructura y función de la huelga en el paso de clase en sí a clase para sí”, en Conflicto Social, Año 2, ํ2 2, Diciembre 2009

Allen, A. (2010). “¿Sustentabilidad ambiental o sustentabilidad diferencial? La reestructuración neoliberal de la industria pesquera en Mar del Plata. Argentina", en Revista de estudios marítimos y sociales; Año 3, № 3, 151158.

Antunes, R. (2007). "Diez tesis sobre el trabajo del presente y una hipótesis sobre el futuro del trabajo", en Revista Realidad Económica, No 232, del 16/11 al 31/12 de 2007, pp. 29-48.

Bertolotti, M., Errazti, E. y Pagani, A (1997). Resultados preliminares del Censo Nacional Industrial Pesquero año 1996. Provincia de Buenos Aires. Plantas instaladas en tierra. Informe técnico interno No 34, INIDEP, Buenos Aires.

Bertolotti, G. y Col (1987). "La actividad industrial pesquera "Procesamiento y Transformación industrial" Capacidades de producción, empleo y posibilidades de aprovechamiento de las especies más importantes del mar argentino. Parte I: Período 1981/1982”, en Revista Contribución No 438, INIDEP: 4-20.

Brunet, I. y Pizzi, A. (2011).Capitalismo y subjetividad obrera. El movimiento de empresas recuperadas en Argentina, Madrid, Biblioteca Nueva.

Colombo, G. \& Nieto, A. (noviembre, 2006). "Bases sociales y económicas de la protesta. La industria de la pesca en Mar del Plata. De la convertibilidad a la devaluación (1991-2002)", Ponencia presentada en XX Jornadas de Historia Económica; Mar del Plata, Argentina.

Colombo, G. \& Nieto, A. (2008). Aproximación a las formas de la lucha obrera en la industria de la pesca, Mar del Plata 1997-2007.LabourAgainPublications, Año 2008, 1 - 15.

Colombo, G. (2008). Hasta que el recurso nos falló. Crisis de la merluza y protesta obrera. La dinámica de los enfrentamientos en el puerto marplatense (1997-2002). Tesina de licenciatura inédita en Historia, UNMDP, Argentina.

Colombo, G. (2014). De la revolución productiva a la crisis de la merluza: El conflicto social en la industria pesquera marplatense. Años 1989-2001". Tesis de posgrado. Universidad Nacional de La Plata. Facultad de Humanidades y Ciencias de la Educación, Argentina.

Cutuli, R. (septiembre, 2009). "Trayectorias laborales precarizadas. Mujeres de la industria pesquera marplatense. 1980-2008”. Ponencia presentada en las II Jornadas de Género y Pobreza, Buenos Aires, Argentina.

Dejours, C. (2013). Trabajo vivo, Tomo II -Trabajo y emancipación, Buenos Aires, Editorial Topia.

Grigera J. (2011). “Desindustrialización, ¿agresión a la manufactura o reestructuración capitalista?”, en Bonnet, A. (comp.) El país invisible: debates sobre la Argentina reciente, Buenos Aires, Peña Lillo/Continente.

Izaguirre, I. (1994). "Problemas metodológicos y construcción de observables en una investigación sobre luchas obreras", en Campione, Daniel (comp). La Clase Obrera De Alfonsín A Menem, Buenos Aires, CEAL.

Lanari, E. \& Cutuli, R (2010). "Trabajadores de la industria pesquera procesadora: conserva y fileteado en el puerto de Mar del Plata", en Concurso El estado de la clase trabajadora en la Provincia de Buenos Aires, Editorial del Ministerio de Trabajo Provincia de Buenos Aires.

Mateo J. (2011).Cosechando el mar en lanchas amarillas, Alemania, Editorial Académica Española.

Mateo, J.; Nieto, A. \& Colombo, G. (2010). "Precarización y fraude laboral en la industria pesquera marplatense. El caso de las cooperativas de fileteado de pescado. Estado actual de la situación y evolución humana de la rama 1989-2010", en Concurso Bicentenario de la Patria: Premio Juan Bialett Massé, Editorial del Ministerio de 
Trabajo de la Provincia de Buenos Aires.

Mateo, J. \& Yurkievich, G. (2010). "Estrategias de la anchoíta en un mar de tiburones: Las pymes conserveras marplatenses durante la valoración financiera (1975-2006)", Trabajos y Comunicaciones (36), 141-164.

Mandel, E. (1977). Introducción al marxismo disponible on-line en http://www.marxistarkiv.se/espanol/clasicos/mandel/introd al marxismo.pdf

Marx, K. (1875). El Capital. Editorial Cartago, Argentina.

Monereo Pérez, J.L (2000). "El Derecho Social en el umbral del siglo XXI: la nueva fase del Derecho del Trabajo", en Lan Harremanak, № 2: 237-300

Nieto, A. (2010). “Amotinados. Ira obrera en la industria pesquera argentina, 1997-2007”, en Revista Lavboratorio, Año XI, Número 23: 95-135.

Nieto, A. (2014). "Industria pesquera y mundo obrero", en Barreneche, O. (Comp.) Historia de la provincia de Buenos Aires. Del primer peronismo a la crisis de 2001, Bs. As., Edhasa/Unipe.

Nogueira, M. L. (2017). "Mar del Plata y Necochea: cara y ceca de la industria pesquera argentina tras la reestructuración capitalista (1970-2013)", en Revista de Estudios Marítimos y Sociales, en prensa.

Nogueira, M. L. (2017). "Políticas públicas para la conservación del empleo en Argentina pos 2002. Los Programas de Recuperación Productiva (REPRO) y de trabajo autogestionado (PTA)", en I Jornadas de Sociología de la UNMDP, Mar del Plata, 30 y 31 de marzo de 2017.

Nogueira, M. L. y Schulze, M. S. (2016). "Conflictividad social y "recuperación” de empresas pesqueras, Necochea/Quequén (2010-2012)", en XI Jornadas de Investigadores en Historia, publicado en Actas de las Jornadas, UNMDP, Mar del Plata, 16 a 18 de noviembre de 2016.

Nogueira, M. L. (2012). "La Recuperada. Primeros pasos en la experiencia de autogestión de trabajadores/as del procesamiento pesquero", en Revista Temas de Patrimonio Cultural 30. Argentina de Puertos III Jornadas Red de Estudios Portuarios, Buenos Aires 2011.

Nogueira, M. L. (2014). "Recuperación de fábricas y subjetividades obreras: el caso de las trabajadoras de Engraucoop (Quequén)", en GRANDE, Eduardo, Cuerpo y subjetividad, $1^{\circ}$ Ed., CABA: Asociación Argentina de Profesionales de la Salud Mental, AASM 2014. (ISBN 978-987-23478-9-5).

Rebón, J., (2004) Desobedeciendo al desempleo. La experiencia de las Empresas Recuperadas, Bs. As., Ed. La rosa blindada y PICASO.

Revista Puerto, La otra cara de la pesca. Octubre de 2010 y marzo de 2011, Mar del Plata.

Piva, A. (2016). "La desorganización de la acción de clase en la Argentina reciente y los problemas conceptuales para el estudio del conflicto obrero", en Estudios Políticos, 48, Instituto de Estudios Políticos, Universidad de Antioquia, pp. 73-93.

Silver, B. (2003). Fuerzas de trabajo. Los movimientos obreros y la globalización desde 1870, Madrid, Ediciones AKAL. 